\title{
Chinese Female Undergraduate's Explicit and Implicit Attitude toward Chinese Skincare Brands and Japanese and South Korean Skincare Brands
}

\author{
Yuanyan Hu1, Shengyan Qiu1, Shaohua Chen1, Jinghui Bi2* \\ ${ }^{1}$ Laboratory of Emotion and Meatal Health, Chongqing University of Arts and Sciences, Chongqing, China \\ ${ }^{2}$ School of Education, Chongqing University of Arts and Sciences, Chongqing, China \\ Email: `bjh0015@163.com, huyypsy@126.com
}

How to cite this paper: Hu, Y. Y., Qiu, S. Y., Chen, S. H., \& Bi, J. H. (2018). Chinese Female Undergraduate's Explicit and Implicit Attitude toward Chinese Skincare Brands and Japanese and South Korean Skincare Brands. Chinese Studies, 7, 1-11. https://doi.org/10.4236/chnstd.2018.71001

Received: November 21, 2017

Accepted: January 12, 2018

Published: January 15, 2018

Copyright @ 2018 by authors and Scientific Research Publishing Inc. This work is licensed under the Creative Commons Attribution International License (CC BY 4.0).

http://creativecommons.org/licenses/by/4.0/

\begin{abstract}
The study aimed to explore the Chinese female college students' attitudes toward skincare brands (including Chinese brands and Japanese and Korean brands) by comparing the results of self-report survey and the Implicit Association Test (IAT). The results showed that participants have inconsistent response patterns in explicit/implicit measures toward Chinese brands and Japanese and Korean brands, and both explicit and implicit attitude measures are significantly differences. That is, participants holds a more positive attitude on Japanese and Korean brands than Chinese brands in explicit attitude, but a more negative in implicit attitude.
\end{abstract}

\section{Keywords}

Brand, Implicit Attitude, Explicit Attitude, IAT, Skincare

\section{Introduction}

Nowadays, China's cosmetics market has been the world's largest emerging markets, and skincare is one of the fastest growing part in this industry. In recent years, China's cosmetics industry sales have been rising at an annual average rate of more than 15\% (China Information Center of Daily Chemical Industry, 2014). Research has shown that female undergraduates are important consuming group (Ding, 2010). Female undergraduates spending for skincare which accounts for $1 / 4-1 / 3$ of their total consumption have been increasing year by year. In addition, female undergraduates pay more attention to basic skincare. 
Therefore, it is particularly important for skincare producers to know the brand that female undergraduates prefer to choose and their attitude towards that brand in order to keep this group. Along with economic globalization, more and more Japanese and South Korean cosmetics enter Chinese market, which offers more options for female undergraduates when it comes to the choice skincare brands. Therefore, to explore female college students' attitude towards a skincare brand can provide references for skincare producers as well as distributors, and offer strong theoretical basis for relevant advertising and marketing.

Attitude refers to the steady, evaluative psychological tendency that the individual holds in response to a particular social object (Zhang, 2008). It is generally acknowledged that attitude includes two types: One is explicit attitude which can be perceived and admitted by people; the other is implicit attitude which is held by people unconsciously and automatically (Wilson, Lindsey, \& Schooler, 2000). Brand attitude refers to the tendency that consumers tend to make a consecutive response (either positive or negative) towards a particular brand, and questionnaire survey is widely adopted to investigate explicit brand attitude in previous studies. For example, Wang (2004) conducted a study with the method of questionnaire survey in order to study multinational retail market and the Chinese local retail store. 334 customers of two stores in the city of Guangzhou took part in the survey, the study finds that domestic customers prefer multinational brands; in order to study overseas sports brand and domestic sports brand, Yang and Wang (2011) conducted a questionnaire survey on 510 undergraduates. They find that undergraduates prefer overseas brands to domestic ones; Yi and Guo (2009) adopted questionnaire survey on 163 MBA postgraduates in Tianjin to study overseas automobile brand and domestic automobile brand and find that domestic car buyers hold better attitude to overseas automobile brands. According to that, most previous studies employ questionnaire survey as the method and find that Chinese customers tend to possess better attitude to overseas brands (Sin, Ho, \& So, 2000; Wang \& Zhao, 2004; Zhuang, Zhou, \& Zhou, 2006). Along with questionnaire survey in the study of explicit brand attitude, a series of indirect measures are taken in the study of implicit brand attitude. For example, Lee and Kim (2013) adopt Self-Report Inventories and IAT (Implicit Association Test) to study American undergraduates' and South-Korean undergraduates' implicit and explicit attitude to fast-food brands, and they find that American undergraduates' implicit attitude to fast-food brands (McDonald's and Burger King) is consistent with explicit attitude while those of South-Korea are not; Feng (2014) employs Semantic Difference Scale and IAT to study undergraduates implicit and explicit attitude to domestic and overseas mobile phone brands, and find that they hold positive attitude to overseas mobile brands explicitly, but there is no obvious preference implicitly. Moreover, undergraduates possess positive attitude to domestic mobile brands explicitly while hold negative attitude implicitly. Most of the researches studied consumers' explicit attitude, but Feng and Kim find that there is a gap between consumers' explicit attitude and their consuming behavior (Feng, 2014; Kim, 
Chiu, Peng, Cai, \& Tov, 2010). And they find that compared with explicit attitude, implicit attitude is a more effective index in predicting consuming behavior (Gattol, Sääksjärvi, \& Carbon, 2011). According to previous studies, the deviation of explicit attitude lies in that the answers were made trims by some participants for fear that the answers do not meet the social expectations (Chen, Nian, \& Wen, 2005; Kim et al., 2010; Ma, 2007; Zhao, Zhou, \& Lin, 2010). With the development of implicit social cognition, consumer psychology can be measured no longer only through explicit behavior and explicit attitude, for that implicit attitude also measure people's consumption behavior to some extent. Besides, compared with explicit attitude, implicit attitude shows stronger stability. According to Greenwald, Mcghee, and Schwartz (1998), implicit attitude is referred to as "traces of past experience that can not be perceived or identified by individual", especially in the study of stereotype and implicit self-esteem (Cai, 2003).

To sum up, the study of brand attitude research has been applied to multiple consumption fields, such as mobile phone brand, sports brand, etc., but it has been rarely found in the study of skincare brand attitude. This study intends to employ standard paradigm of IAT and questionnaire survey to investigate female undergraduates' explicit and implicit attitude to skincare brands both at home and abroad in order to enrich relevant theories of brand attitude and at the same time, provide a reference for skincare marketing practice.

\section{Method}

\subsection{Chinese Female Undergraduate's Explicit Attitude toward Brands of Skincare}

\section{1) Participants}

We send out 183 questionnaires through network and get 183 questionnaires back. Then we examed the time the survey took to complete and the data integrity to ensure the questionnaires' validity. Excluding the 13 males' and 19 invalid questionnaires, there were 151 valid questionnaires with a returning rate of 82.6\%. The participants range from 19 to 22 years old $(M=20.34, S D=1.14)$.

\section{2) Measures}

Firstly, questionnaire of the usage of skincare products is made. The questionnaire includes three parts, namely, demographic variables, brand choice and attributes. And demographic variables cover gender, grade, cost of living, frequency of use of skincare and preference of skincare brand.

Secondly, 20 positive words and 20 negative words are extracted respectively from three big shopping websites, namely Tmall, Jumei and Jingdong. 15 female undergraduates who are familiar with skincare brands are asked to rate the 40 words, and pick out ten positive and negative words respectively. The positive words are: reliable, gentle, delicate, high-end, efficient, innovative, authentic, qualified, advanced, and natural while the negative words are questionable, irritative, rough, mediocre, invalid, old, fake, counterfeit, backward, and chemical. 
Also these 20 words are used as implicit experimental material.

According to relevant studies, Semantic Difference Scale is employed to measure female undergraduates' explicit brand attitude (Su, 2014; Yuan, Luo, \& Ye, 2009). That is, participants are asked to grade domestic skincare brand and Japanese \& Korean skincare brand respectively with " $-3,-2,-1,0,1,2,3$ ". The table includes 10 items which are related with brand attitude.

\subsection{Chinese Female Undergraduate's Implicit Attitude toward Brands of Skincare}

\section{1) Participants}

Questionnaires are send out through network and 190 questionnaires are got back, excluding 29 males, and finally the remaining 161questionnaires are valid female ( $M$ age $=20.05, S D=1.25)$.

127 female undergraduates of Chongqing University of Arts and Sciences who are familiar with Chinese and Japanese and South Korean skincare brands are recruited in the experiment, and all of the participants have a normal to correct vision with no color deficiency, and all the participants are well versed in computer operation.

2) Materials

The Implicit Association Test (Implicit Association Test, IAT) contains two kinds of materials: skincare brands and attributes. On the basis of brand familiarity (i.e., participants rated the familiarity of each brand using a 5-point Likert scale, in which "1" represents not familiar at all, and " 5 " represents very familiar), 10 Chinese skincare brands and 10 Japanese and South Korean skincare brands are selected respectively according to the 161 questionnaires. The Top 10 Chinese skincare brands are Pechoin (百雀羚), Dabao (大宝), Kans (韩束), Longliqi (隆力奇), MG (美即), Proya (珀莱雅), Sinoway Herb (相宜本草), Yumeijing (郁美净), Yunifang (御泥坊), Chando (自然堂) and the Top 10 Japanese \& Korean skincare brands are SK-II, The Face Shop (菲诗小铺), MISSHA (谜尚), Skin Food, Mamonde (梦妆), Aupres (欧珀莱), Innisfree (悦诗风吟), LANEIGE (兰芝), Za (姬䒘), Sekkisei (雪肌精). The results showed that the brand familiarity's mean score of the 10 Chinese skincare brands and 10 Japanese and South Korean skincare brands were 2.88 and 2.13 respectively. Although the differences of the brand familiarity's mean score existed between the two kinds of brands, the size of the differences were in the range of acceptance. Then 20 brand cards are made respectively with pixels of $500 \times 500$ and resolution ratio of 300 ppi. Brand logo and typical products of each brand are included in the card.

20 words, both positive and negative, in the study of explicit attitude are employed as attributes. The 10 positive words are: reliable, gentle, delicate, highend, efficient, innovative, authentic, qualified, advanced, and natural while the 10 negative words are questionable, irritative, rough, mediocre, invalid, old, fake, counterfeit, backward, chemical. 


\section{3) Procedure of the IAT}

Inquisit 3.0 is adopted in writing IAT programs, and Greenwald's seven sections of the standard paradigm is used (See Table 1). Firstly, participants are required to categorize the target concepts. For example, press " $E$ " button when the image of domestic skincare brand appears and press "I" button when the image of Japanese and South Korean skincare brand occurs. Secondly, classify the attributes. That is, press "E" button when positive words appears and press "I" button when negative words occurs. Thirdly, make a joint discrimination; that is, the participants are required to classify positive words and the image of domestic skincare brand as one kind and press "E" button while classify negative words and the image of Japanese\& Korean skincare brand as one kind and press "I" button. Fourthly, repeat step three. Fifthly, reverse step one, that is, press "E" button when the image of Japanese \& Korean skincare brand occurs and press "I" button when the image of domestic skincare brand appears. Sixthly, reverse step three. That is, classify positive words and the image of Japanese and South Korean skincare brand as one kind and press " $\mathrm{E}$ " button while classify the image of domestic skincare brand as one kind and press "I" button. Seventhly, repeat step six.

\section{4) Pre-processing of IAT}

According to Greenwald, Nosek, and Banaji (2003), the participants whose average accuracy is lower than $80 \%$ is deleted; $10 \%$ of whose response time are less than $300 \mathrm{~ms}$ as well as that are more than $1000 \mathrm{~ms}$ are deleted. Meanwhile, response time of false response.

After that, 121 valid participants are left. The overall standard deviation of two exercise tasks (Block $3 \&$ Block 6) and two key tasks (Block $4 \&$ Block 7) are got

Table 1. Procedure of the IAT.

\begin{tabular}{|c|c|c|c|}
\hline \multirow{2}{*}{ Block } & \multirow{2}{*}{ Task Description } & \multirow{2}{*}{ Stimulus \& Response Key } & \multirow{2}{*}{$\begin{array}{l}\text { No. of } \\
\text { trials }\end{array}$} \\
\hline & & & \\
\hline 1 & $\begin{array}{l}\text { Target Compatible } \\
\text { Practice }\end{array}$ & $\begin{array}{c}\text { Domestic Skincare Brand(E) } \\
\text { Japanese and South Korean Skincare Brand(I) }\end{array}$ & 20 \\
\hline 2 & Attribute Practice & Positive Words(E) Negative Words(I) & 20 \\
\hline \multirow{3}{*}{3} & \multirow{3}{*}{ Compatible Test } & Positive Words or Domestic Skincare Brand(E) & \multirow{3}{*}{20} \\
\hline & & Negative Words or Japanese and & \\
\hline & & South Korean Skincare Brand(I) & \\
\hline 4 & Compatible Test & Same as Block 3 & 40 \\
\hline \multirow[t]{2}{*}{5} & $\begin{array}{c}\text { Target Incompatible } \\
\text { Practice }\end{array}$ & $\begin{array}{l}\text { Japanese and South Korean Skincare } \\
\text { Brand(E)Domestic Skincare Brand(I) }\end{array}$ & 20 \\
\hline & & Positive Words or Japanese and & \multirow{3}{*}{20} \\
\hline \multirow[t]{2}{*}{6} & Incompatible Test & South Korean Skincare Brand(E) & \\
\hline & & Negative Words or Domestic Skincare Brand(I) & \\
\hline 7 & Incompatible Test & Same as Block 6 & 40 \\
\hline
\end{tabular}


respectively, and then the reaction time of Block 6 minus the reaction time of Block 3 and divided by standard deviation of exercise task, we got the data of $D_{1}$. The reaction time of Block 7 minus the reaction time of Block 4 and divided by standard deviation of key task, we got the data of $D_{2}$, and $D$ is the mean of $D_{1}$ and $D_{2}$.

Of all the steps mentioned, step one, step two and step five are exercises, and when mistake occurs, the participants are informed accordingly; step three and step six are exercise tasks; step four and step seven are key tasks, and the two steps are compatible and incompatible respectively. The probability that compatible task occurs either before or after incompatible task is even, and which one comes first is decided randomly. Computer will automatically record the reaction time and reaction accuracy each time.

The participants complete all the steps independently following the instructions. Each time the target words and attribute words combine into a pair while the position of target words and attribute words are not fixed, that is either of a target word and an attribute word may occur on the left side as well as on the right side.

\section{Results}

\subsection{Chinese Female Undergraduate's Explicit Attitude toward Brands of Skincare}

Statistical analysis is made according to the questionnaires, and the findings are as follows:

1) In terms of usage frequency, female undergraduates who never use, rarely use, use occasionally, very often, and use everyday were $1.32 \%, 8.61 \%, 21.85 \%$, $18.54 \%, 49.67 \%$ respectively. In other words, female participants who use skincare everyday or very often accounts for $68.21 \%$. In terms of choice preferences about Chinese skincare brands and Japanese and South Korean skincare brands (a multiple choice question), female undergraduates who choose Chinese skincare brands, Japanese and South Korean skincare brands, and other kinds of skincare brands were $64.9 \%, 50.99 \%$, and $25.17 \%$ respectively. These results indicated that Chinese skincare brands are the most preferred of female undergraduates, and Japanese and Korean skincare brand preferred slightly lower than the Chinese skincare brands. Therefore, we could ensure that the sample representative of this study is credible.

2) In terms of explicit attitude, average score of female undergraduates to domestic skincare brands is 0.297 ( $S D=.791$ ), while that of Japanese and Korean skincare brands is $0.779(S D=.675)$.

Table 2. Description statistics of four test blocks.

\begin{tabular}{ccccc}
\hline & Block 3 & Block 4 & Block 6 & Block 7 \\
\hline$M$ & 1327.65 & 1110.60 & 1455.61 & 1177.98 \\
$S D$ & 423.46 & 233.20 & 407.52 & 315.40
\end{tabular}


Results of paired-samples $T$ test shows that the score difference of female undergraduate's explicit attitude to domestic skincare brands and Japanese and Korean skincare brands is significant $(t=-4.351, p<.001)$. That is, in terms of explicit attitude, female undergraduates show more positive attitude to Japanese and Korean skincare brands compared with domestic skincare brands.

\subsection{Chinese Female Undergraduate's Implicit Attitude toward Brands of Skincare}

Implicit attitude: In terms of compatible classification (Block3 and Block4 in Table 2), participants' reaction time are relatively short, and when it comes to incompatible classification (Block 6 and Block 7 in Table 2), participants' reaction time are relatively long. Paired-samples $t$ test are conducted on reaction time of "practices" and that of "task". According to paired-samples $t$ test, the participants' reaction time have a significant difference between that of "practice" $(t=-2.987, p<.005)$ and "task" $(t=-2.233, p<.05) . D$ score is 0.13 (SD $=.48)$. The bigger of the $D$ score, the more obvious of female undergraduates' implicit attitude. That is, their implicit attitude are more close to compatible classification, i.e. domestic skincare and positive words. Independent-samples $T$ test is performed on $D$ score $(t=2.91, p=.004)$.

As Table 2 shows, the image of skincare and attribute words in Block 3 and Block 4 are consistent with individual's self-schema, which belongs to compatible classification. The average reaction $(M=1110.60 \mathrm{~ms}, S D=233.20 \mathrm{~ms})$ time is short; As to Block 6 and Block 7, it is the opposite of that of Block 3 and Block 4 , belonging to incompatible classification. The average reaction time ( $M=1178$ $\mathrm{ms}, S D=315.40 \mathrm{~ms}$ ) is relatively long. According to the data, it is found that the participants perform faster when it comes to compatible task $(t=-2.233, p$ $=.027)$, that is, participants' reaction time $(M=1110.6 \mathrm{~ms})$ are shorter in compatible classification task, namely classifying domestic skincare brand with positive words. However, in the incompatible classification task of Japanese \& Korean skincare brand and positive words, participants' reaction time ( $M=1177.98$ ms) are obviously longer.

In order to know how the preference of implicit attitude to skincare brand is, the switch of $D$ score is conducted. The bigger the $D$ score, the higher degree of implicit attitude is. In this experiment, the $D$ score is $0.18(S D=.48)$, which is greater than $0(t=2.908, p=.004)$. From that, it can be seen that female undergraduates shows slight preference to domestic skincare, and the IAT effect is significant. That is, the participants' implicit attitude to domestic skincare brand is positive.

\section{Discussions}

\subsection{Chinese Female Undergraduate's Explicit Attitude toward Brands of Skincare}

The study of explicit attitude to skincare brand shows that female undergra- 
duates tend to associate Japanese and South Korean skincare brand with positive words, detached from negative words, which is consistent with Yang and Wang (2011) study on undergraduates' explicit attitude to sports brands, as well as Yi and Guo (2009) study on explicit attitude on automobile brands. It may lie in that undergraduates' consuming behavior is highly influenced by advertising and brand effect, and tend to show more recognition to overseas brands. Besides, there exist conformity consumption and typical characteristics of perceptual consumption in the choice of skincare brands (Yang \& Wang, 2011). Thus, female undergraduates are inclined to choose overseas brands in terms of explicit brand attitude.

\subsection{Chinese Female Undergraduate's Implicit Attitude toward Brands of Skincare}

According to the statistical analysis of the reaction time, female college students are more inclined to associate domestic brands with positive words, detached from negative words, which is consistent with Feng (2014) study on undergraduate's implicit attitude on cellphone brands. The reasons may be that female undergraduates are more familiar with domestic brands (According to the questionnaire, the gap between the score of domestic skincare brand and that of overseas in terms of familiarity), and they react more quickly to domestic skincare brands (Zhao et al., 2010). However, that is the opposite of Dimofte, Johansson, and Ronkainen (2008) study on Americans implicit brand attitude. That may lie in that their consumption concepts are different: Firstly, influenced by individualism, Americans attach importance on individual needs and the pursuit of novelty, so they tend to choose bargains from developing countries while influenced by collectivism, Chinese are apt to affect by group and tend to associate consumption with national emotions (Ji, 2006); secondly, according to cross-race study, there are differences in the representation of implicit and explicit attitude between different ethnic groups (Blair, Judd, Havranek, \& Steiner, 2010; Daeyoung \& Chen, 2010).

\section{General Discussion and Implications}

\subsection{General Discussion}

In terms of explicit attitude, female undergraduates are inclined to show positive attitude to domestic skincare brands as well as Japanese and South Korea brands. At the same time, relevant studies suggest that Chinese consumers have formed a strong local negative stereotype and positive stereotype of foreign brands (Liu, Zhang, \& Zhang, 2014), which is consistent with our explicit attitude measurement results. However, when it comes to implicit attitude, the implicit effect value reflects the association between domestic skincare brands and positive properties are much closer.

As for the inconsistency between explicit attitude and implicit attitude, previous studies have put forward the interpretation of the identity theory and the 
theory of separation. Greenwald et al. (2002) believe that in the following two cases in two cases there exist isolation between implicit and explicit attitude: 1) individual will cause social needs, and his or her explicit attitude is consistent with the idea of consciousness desire; 2) when the attitude object has not been processed and not connected with the idea of unconsciousness, implicit and explicit attitude is isolated. Nowadays, more and more female undergraduates exhibit strong purchasing power on skincare, and skincare help to fulfill more social need than basic care (Feng, 2014). Thus, there is separation of implicit and explicit attitude.

\subsection{Implications}

According to the research findings, female undergraduates hold different attitudes towards domestic skincare brands and Japanese and South Korean skincare brands. Besides, different marketing strategies are made according to dual attitude model of attitude separation:

In this study, Japanese and South Korean skincare brands score higher than domestic skincare brands in terms of explicit attitude. And findings of a meta-analysis research shows that predictive power of explicit attitude is stronger than that of implicit attitude (Hofmann, Gawronski, Gschwendner, Le, \& Schmitt, 2005; Hofmann, Gschwendner, \& Schmitt, 2005). Besides, explicit attitude has better predictive power on behaviors that can be controlled by consciousness (Liu \& Sang, 2010; Tu, Yang, \& Xing, 2013). Thus, in the marketing of Japanese and South Korean skincare, the advantage of explicit attitude can be made use of to achieve marketing purpose, and try to make the customer be aware of his or her behavior in the choice of skincare brands by letting the customer know more about its quality, composition and cost performance.

Chinese skincare brands score higher than Japanese and Korean skincare brands in terms of implicit attitude, and implicit attitude has stronger predictive power than explicit attitude on behaviors that can not be controlled by consciousness (Liu \& Sang, 2010). Thus, in the marketing of domestic skincare, the advantage of implicit attitude can be made use of, and try to make the customer not be aware of his or her behavior. For example, interesting packaging can be employed to arouse customer's curiosity and impulse buying. Besides, some high cognitive load games (such as arithmetic, mind quiz.) can be used to consume the cognitive resources of customers, and hot issues (such as boycotting Japanese goods, restrictions on Korea, etc.) can also be employed to arouse customers' national feelings.

\section{Conclusions}

First, in terms of explicit attitude, female undergraduates exhibit a more positive attitude towards Japanese and South Korean skincare brands, and a more negative attitude towards domestic brands.

Second, in terms of implicit attitude, female undergraduates exhibit a more 
positive attitude towards domestic skincare brands, and a more negative attitude towards Japanese and South Korean skincare brands.

\section{Funding}

This research was supported by the grant from Chongqing University of Arts and Sciences (No. 140307).

\section{References}

Blair, I. V., Judd, C. M., Havranek, E. P., \& Steiner, J. F. (2010). Using Community Data to Test the Discriminate Validity of Ethnic/Racial Group IATs. Zeitschrift Für Psychologie, 218, 36-43. https://doi.org/10.1027/0044-3409/a000006

Cai, H. (2003). A Review on Implicit Association Test. Advances in Psychological Science, 11, 339-344. (In Chinese)

Chen, Q., Nian, C., \& Wen, Z. (2005). Impression Management and the Effect of Implicit Attitude. Psychological Science, 28, 634-635. (In Chinese)

China Information Center of Daily Chemical Industry (2014). Skin Care Product Industry Development in China. Detergent \& Cosmetics, 7, 11-13. (In Chinese)

Daeyoung, K., \& Chen, Z. (2010). Are People Aware of Their Attitudes toward Destination? Understanding the Implicit Association Test in Tourism Research. Tourism Analysis, 15, 299-313. https://doi.org/10.3727/108354210X12801550666060

Dimofte, C. V., Johansson, J. K., \& Ronkainen, I. A. (2008). Cognitive and Affective Reactions of U.S. Consumers to Global Brands. Journal of International Marketing, 16, 113-135. https://doi.org/10.1509/jimk.16.4.113

Ding, J. (2010). Female College Students Investigate the Brand Consciousness of Skin Care Products. Consumption and Market, 7, 36-37. (In Chinese)

Feng, J. (2014). The Study of Consumer Behavior Prediction by Implicit Attitude of Consumers. Master, Nanjing: Nanjing Normal University. (In Chinese)

Gattol, V., Sääksjärvi, M., \& Carbon, C. C. (2011). Extending the Implicit Association Test (IAT): Assessing Consumer Attitudes Based on Multi-Dimensional Implicit Associations. Plos One, 6, e15849. https://doi.org/10.1371/journal.pone.0015849

Greenwald, A. G., Banaji, M. R., Rudman, L. A., Farnham, S. D., Nosek, B. A., \& Mellott, D. S. (2002). A Unified Theory of Implicit Attitudes, Stereotypes, Self-Esteem, and Self-Concept. Psychological Review, 109, 3-25.

https://doi.org/10.1037/0033-295X.109.1.3

Greenwald, A. G., Mcghee, D. E., \& Schwartz, J. L. (1998). Measuring Individual Differences in Implicit Cognition: The Implicit Association Test. Journal of Personality \& Social Psychology, 74, 1464-1480.

https://doi.org/10.1037/0022-3514.74.6.1464

Greenwald, A. G., Nosek, B. A., \& Banaji, M. R. (2003). Understanding and Using the Implicit Association Test: I. An Improved Scoring Algorithm. Journal of Personality and Social Psychology, 85, 197. https://doi.org/10.1037/0022-3514.85.2.197

Hofmann, W., Gawronski, B., Gschwendner, T., Le, H., \& Schmitt, M. (2005). A Meta-Analysis on the Correlation between the Implicit Association Test and Explicit Self-Report Measures. Personality and Social Psychology Bulletin, 31, 1369-1385. https://doi.org/10.1177/0146167205275613

Hofmann, W., Gschwendner, T., \& Schmitt, M. (2005). On Implicit-Explicit Consistency: the Moderating Role of Individual Differences in Awareness and Adjustment. European Journal of Personality, 19, 25-49. https://doi.org/10.1002/per.537 
Ji, Y. (2006). The Cross-Cultural Study of Shopping on the Influence of Chinese and American Cultural Differences on Consumers. Journal of Beijing Institute of Foreign Languages (Foreign Language Edition), 8, 69-74. (In Chinese)

Kim, Y., Chiu, C., Peng, S., Cai, H., \& Tov, W. (2010). Explaining East-West Differences in the Likelihood of Making Favorable Self-Evaluations: The Role of Evaluation Apprehension and Directness of Expression. Journal of Cross-Cultural Psychology, 41, 62-75. https://doi.org/10.1177/0022022109348921

Lee, K., \& Kim, D. (2013). A Comparison of Implicit and Explicit Attitude Measures: An Application of the Implicit Association Test (IAT) to Fast Food Restaurant Brands. Tourism Analysis, 18, 119-131. https://doi.org/10.3727/108354213X13645733247576

Liu, J., \& Sang, B. (2010). Implicit-Explicit Attitudes and Behavioral Predictability. Journal of East China Normal University (Educational Sciences), 28, 59-66. (In Chinese)

Liu, J., Zhang, Y., \& Zhang, R. (2014). Explicit Measurement and Analysis of Chinese Consumer Brand Origin Stereotypes. Enterprise Economy, 1, 21-24. (In Chinese)

Ma, M. (2007). An Experimental Study on the Effect of Implicit Attitude on Consumer Behavior. Shanghai: East China Normal University.

Sin, L. Y. M., Ho, S. C., \& So, S. L. M. (2000). Research on Advertising in Mainland China: A Review and Assessment. Asia Pacific Journal of Marketing \& Logistics, 12, 37-65. https://doi.org/10.1108/13555850010764631

$\mathrm{Su}, \mathrm{H}$. (2014). Ethnic Stereotypes of Uyghur and Han University Students: Explicit and Implicit. China Youth Study, No. 12, 21-24. (In Chinese)

Tu, Y., Yang, Z., \& Xing, X. (2013). The Influence of Explicit and Implicit Attitude toward Consumers' Sustainable Purchase Intention. East China Economic Management, 27, 132-138. (In Chinese)

Wang, H., \& Zhao, P. (2004). Country of Brand Effect: An Empirical Study in China and Its Marketing Managerial Implications. China Industrial Economy, No. 1, 78-86. (In Chinese)

Wang, W. (2004). A Comparative Study of Consumer Attitudes towards Chinese and Foreign Retail Brands. Business Economics and Administration, No. 10, 11-15. (In Chinese)

Wilson, T. D., Lindsey, S., \& Schooler, T. Y. (2000). A Model of Dual Attitudes. Psychological Review, 107, 101-126. https://doi.org/10.1037/0033-295X.107.1.101

Yang, L., \& Wang, P. (2011). Research on Attitude and Consumption Behavior of College Students in Changsha City: Taking Sports Brand as an Example. Jiangsu Commercial Forum, 6, 44-45. (In Chinese)

Yi, M., \& Guo, J. (2009). Research on Influence of Country-of-Brand toward Chinese Automobile Buyer's Brand Attitude. Economic Management Journal, 31, 94-102. (In Chinese)

Yuan, D., Luo, S., \& Ye, J. (2009). A Research on the Separation between the Implicit Brand Attitude and the Explicit Brand Attitude. Psychological Science, 32, 1298-1301. (In Chinese)

Zhang, Z. (2008). Social Psychology. Beijing: People's Education Press. (In Chinese)

Zhao, Z., Zhou, Z., \& Lin, S. (2010). Culture and Socially Desirable Responding: An Individual-in-Society Perspective. Acta Psychologica Sinica, 42, 48-55. https://doi.org/10.3724/SP.J.1041.2010.00048

Zhuang, G., Zhou, N., \& Zhou, L. (2006). National-Brand Consciousness, Brand Characteristics, and Consumers' Preference for Indigenous Brands. Management World, No. 7, 85-94. (In Chinese) 